\title{
EDITORIAL
}

\section{The Viable Culture}

Something is wrong. The human response-system is failing. The glacial pace of reaction to world-wide environmental degradation threatens all life.

While humans have been manipulating the natural environment since the beginning of agriculture, the impact has suddenly become world-wide and severe. Around the middle of this century, the combination of ever-growing human populations and more and more powerful technologies overwhelmed the ability of natural systems to maintain their balance. We humans now have the power to extinguish any or possibly all species at least of higher biota. In the pursuit of our daily activities, we are unwittingly destroying the lifesupport systems of our own and future generations.

We have failed to recognize the fact that human dominance has become virtually absolute, and that, as a result, we have entered a new watershed in human history in which we are the primary determinants of the future of life on Earth. The significance of this unique situation is yet to be appreciated. As a result, there is no movement towards basic change; and the news of each additional environmental disaster is met with embarrassment and ad hoc solutions.

Yet there is an intuitive sense of malaise. The threat of nuclear war or major accident, and the continuing degeneration of the environment, have deprived us of a predictable future. This sense of futurelessness encourages the pursuit of immediate satisfactions and short-term goals. It contributes to our social problems, interferes with long-term planning and investment, and encourages a dangerous sense of individual helplessness.

\section{The Disabling Culture}

We are disabled from effective action on behalf of ourselves and our environment by the persistence of a culture that no longer fits our unique situation. The international economic culture of the developed nations continues to determine decisions in business, government, and private life. The assumptions of that culture - assumptions that were useful as we conquered one natural obstacle after another - now prevent us from adapting to current realities. Our exploiting-attitudes towards Nature, for example, are contradicted by our biological dependence. Our enthusiasm for technology, growth, and development, is now yielding a harvest of side-effects that overwhelm their benefits. We have taken life for granted, only to find that we are now responsible for its future.

A major difficulty is that these assumptions are part of the culture on which we have been weaned - that has taught us human speech and custom, that has given us education and supplied the field for the exploration of our talents. For many in the developed world it has provided food, clothing, and housing so convenient and comfortable that we hardly notice the changing of the seasons.

Often these 'achievements' were based on the piecemeal subjugation of the natural environment. When we were less numerous and the means were less powerful, the effects were largely local and seemed justified by the benefits. Now we are beginning to realize that the Earth's natural systems are overwhelmed, that power pollutes and chemicals kill, and that we have not tamed the power of the atom, but spread its poisons around the world.

And we cannot accept it.

Again and again, goverments send their scientists back to reexamine the deterioration of the ozone layer, the causes of acid rain, the likelihood of the greenhouse effect, and the severity of a foreseeable "nuclear winter'. For political and business decision-makers in our society, information is not enough. Without a meaningful context, the degeneration of the environment is just one more problem to be handled on a cost/benefit basis.

The accelerating degeneration of the environment, and the continuing accumulation of nuclear weapons, are symptoms of the critical misfit of modern culture to our unique human situation. We can delay no longer. For the sake of our children and the environment in which they must live, we must have a new culture.

\section{Changing our Culture}

In the past, cultures have been changed by military conquest, religious conversion, and ever-changing elites and technologies. World-wide environmental decline will produce a compensating culture, eventually. If we wait for additional deterioration to force the change, innumerable species will be lost, the damage to systems may be irreversible, and our humanity will be severely degraded by the triage of human populations. 
The pendulum swings. We in the developed world have had our intoxication with human progress, our day of arrogance. Now the pendulum hesitates before returning to a consciousness of human limitations and dependence on the rest of Nature.

We need not wait. The creativity that developed the technology to accelerate through gravity and put people on the Moon, is capable of developing the cultural acceleration necessary to overcome old attitudes and hasten our adaptation to environmental realities.

The first requirement is a keen awareness of the problem: our goals and values are suicidal because the assumptions on which they are based have been rendered obsolete by humanity's recent domination of The Biosphere.

The second requirement is the courage to face our precarious future creatively without attachment to any particular aspect of the existing culture. All previous world views must be regarded with scepticism, because they are based on the outdated assumption that life will continue regardless of human activities.

\section{The Culture We Need}

The problem of human survival has become a problem, inter alia, of inhibition. Becauise we have the power to do many things does not mean automatically that they should be done; the use of nuclear weapons and the clearing of the Amazon basin are obvious examples. Yet prohibition is notoriously ineffective.

The universal motivation for change is the search for a better life. A life-centred, future-oriented culture must be a positive vision activated by our common desires to survive, to procreate, and to be approved by others. It must offer opportunities for individual creativity and expression; and it must embrace every human being, so that we do not lose our rights or our humanity during the difficult transition to come.

Because life itself is in trouble, the Viable Culture looks to biology for many of its concepts and patterns. The other source of the principles has been the search for antidotes to the toxic habits of thought and action that have led to the current destruction.

The Viable Culture is envisioned as a permeating world view that would enable Mankind to foster the continuation of all life into the distant future - not as specimens in zoos, botanical gardens, or survival shelters, but in the varied and complex environments which are necessary for continued evolution.

During the transition to a symbiotic relationship with the rest of Nature, there will be conflict between short-term human needs and the long-term needs of the environment. The deepening crisis threatens our humanity as well as our future. To maintain a balance between those essential considerations, both are expressed as goals of the Viable Culture.

\section{The Goals}

I. The Continuation of All Life Into the Distant Future:- This may be stated more precisely as the reduction of the rate of extinction of species to the average of the last ten thousand years.

II. The Preservation of our Humanity: - The Universal Declaration of Human Rights can serve as a guide to the treatment of peoples during the transition period.

While the desirability of these goals is recognized by modern society, they are frequently overrun by the central economic goals of modern consumerism. The task of the Viable Culture is to reverse these priorities and place the life-oriented goals at the centre of our consciousness. The following principles are proposed to expand, clarify, and support, these goals.

\section{The Principles}

The Manture Concept:- It is essential that all peoples discard their arrogant and alienated attitudes towards Nature. The joined word 'manture' stands for the natural origins of humanity, the spontaneity towards Nature of every living person, and the dependence of all people on the rest of Nature. It thus symbolizes the unity of Humanity and Nature. The facts are common knowledge, but until they form the essence of our concept of self and our true relationships to the living world around us, we will continue to abuse both ourselves and the environment.

We Are the Living Future:- We, and all the other organisms living on Earth at this moment, are the basis for all future life - to the extent that no other form of life is known to exist elsewhere in the Universe. From this perspective we have more in common with the lowliest procaryotic cell than with the vast multitudes of the extinct or dead. As every person now influences the condition of The Biosphere, we all participate in making the future - whether we have children or grandchildren or not. This is an awesome responsibility and, at the same time, a vital source of meaning in the life of every individual.

Human Allegiance:- The many-layered interactions between all people in the world today emphasize the limits of nationalism. The health of The Biosphere demands health in all of its parts. While achieving our own balance with Nature, we must help others to do the same. Our humanity and our survival require a heightened identification with people around the world.

Treasuring Diversity:- The diversity of species and cultures is the great heritage of life, yet we destroy them on practically a regular basis. We are disinheriting future generations of riches that have not even been appraised. We must find the wisdom to accept that, because we do not know which soil organisms, plants, insects, or ways of life, may be the key to future problems, all are potentially valuable. 
Unity of Organism and Environment:- We are still trying to save the whales without 'saving' the oceans. Most people see the living world as an assemblage of individual organisms, without sufficient awareness of the continuous interactions with their surroundings that determine their character, viability, and future. We must learn to 'see' the unity of organism and environment, and indeed of the world as a whole.

Mutuality:- To provide for human needs without degrading the natural environment will require new attitudes and fresh vigilance in choice and action. We must learn to act in ways that both satisfy human needs and, at the same time, enhance the vigour and diversity of the natural world. In the long run, only such symbiotic activity can survive. It requires a sense of our existence being shared with all living things - a mutuality akin to that of indigenous peoples with their land and its creatures.

Thinking in Cycles and Systems:- To avoid the surprise of damaging side-effects emanating from future actions, we must learn to think in terms of complete cycles and systems - to consider at once the physical, biological, and social, results of our actions. By patterning our thinking and concomitant actions after the complex interactions of enduring natural systems, we may emulate their ability to survive.

These principles of the Viable Culture offer the beginnings of a world view that goes beyond materialistic concerns and centres our awareness on life itself. The technology that has given us the power to destroy life has also given us the tools for survival. We have the world-wide communications on which to base our identification with all people. Our increasing knowledge of the environment can be the basis for a symbiotic relationship. How we use our knowledge and technology will be determined by our culture and application.

\section{Making the Viable Culture}

An intentional collaboration between bioscientists, educators, and creative artists, can accelerate the swing of the cultural pendulum towards a more viable way of life than that which our profligate species has thrust on this fragile planet. The urgency of the situation calls for unusual efforts to transcend the barriers between science and its alternatives. Bioscientists can provide creative people with the information and principles necessary for the equable continuation of life, and others can execute the necessities while artists, in turn, can create the new forms that may give wide-ranging cultural expression to vital ecological concepts.

Participants should find that such collaborations can be exciting. Thus a concept proposed by an ecologist may become something quite unexpected when creatively expressed by a painter or writer. Each individual will tend to do the job differently, asking different questions that can become the stimulus for new approaches to environmental research; for the arts are well suited to express the complex relationships of living things.

Another role of the arts is to make the unseen visible, audible, or deeply felt. One of the reasons for our slow response to environmental problems is their general invisibility. We cannot see the acid in rain, the carbon dioxide in the air, or the CFCs attacking the stratospheric ozone shield. We tend to preserve the illusion of our independence from the rest of Nature by ignoring its invisible support of our daily lives. These relationships can become more meaningful through their expression in the arts.

Many artists are concerned nowadays with the environment: they need the stimulation and encouragement of those who know the problems best. An international exhibition of visual art that expresses the principles of the Viable Culture would encourage the creation of new kinds of painting, sculpture, and photography. It would also involve art-interested people in the manifold challenges created by our unique human situation.

An international film festival organized around the Viable Culture would, we believe, attract world-wide interest. A special challenge is the need to create a new kind of hero. The one-man vigilante battling evil with violence is unsuited to the expression of life-nurturing values.

The creation of a new culture that fits our needs in this unique era of human history is a vast creative challenge. How that challenge is met at all levels of human awareness and activity will inevitably determine the future of Humankind and Nature.

\section{Education}

While the continuity of culture from one generation to another is the basis of human achievement, the uncritical and often unconscious transmission of traditional values and assumptions may disable our young people from coping with the unique problems which they have to face. Schools are in a difficult position, because many of today's children spend thousands of hours before the luminous images and 'authoritative' voice of television before starting school. In the US this means that they have been indoctrinated with consumer values during the period of basic character-formation.

To enable them to participate in the transformation of our society into a more viable system, they will need a deep appreciation of Nature as the source, provider, and continuing partner, of human life. Yet, for most of the urban population, the alienation from Nature is so nearly complete that ecological principles have little meaning. For those who have never known a forest, the destruction of rain forests is the merest abstraction. How does one teach the bounty of Nature to youngsters who have never picked ripe fruit from a tree or tasted fresh vegetables from a garden - or, still worse, have never walked in the country or visited a seashore? 
In an artificial, Man-made environment, education must supply the essential experience and knowledge that once were provided by rural life. Perhaps every classroom should be a vivarium offering each child an opportunity to participate in the nurture of living things.

Our newly-acquired responsibility for the future of life demands that extraordinary ways be found to bring the basic principles of life into the very centre of the educational experience.

\title{
An Appeal
}

The Viable Culture is a developing concept; the urgency of the situation suggests that it should be shared as it is made, a piece at a time. Readers of this Editorial are invited to participate in its development by reaching out to educators and artists, and by submitting frank criticisms and suggestions for improvement to the Authors.

After a quarter-century-long battle inter alia by the founding Editor of this Journal and of its surviving predecessor, Biological Conservation, there is at last a rapidly-rising consciousness of environmental problems practically throughout the world, and many useful local programmes are under way. There are also numerous conferences, such as the International Conferences on Environmental Future under the same auspices as this Journal, and special projects to deal with such global scourges as climatic warming and its effects, stratospheric ozone-shield depletion, further build-up of nuclear arsenals which could devastate the world, and of the basic ones of human overpopulation and profligacy.

What is still lacking is a clear vision of the future on which to base the consensus which is necessary for concomitant human-engendered counteraction, and for that inculcation of adequate realization that the environment constitutes the key to our own and Nature's destiny, with life its most fundamental feature to be preserved foremost and always. That we can effect such change seems to be amply demonstrated by the proven ability of Mankind to adapt to the myriad environments of the Earth - which in turn constitutes encouraging evidence that we can adapt further to the unique situation of our own pandominance.

\author{
PETER COHEN \\ RD 6 BOX 6198 \\ Stroudsburg \\ Pennsylvania 18360 \\ USA, \\ $\&$ \\ Nicholas Polunin
}

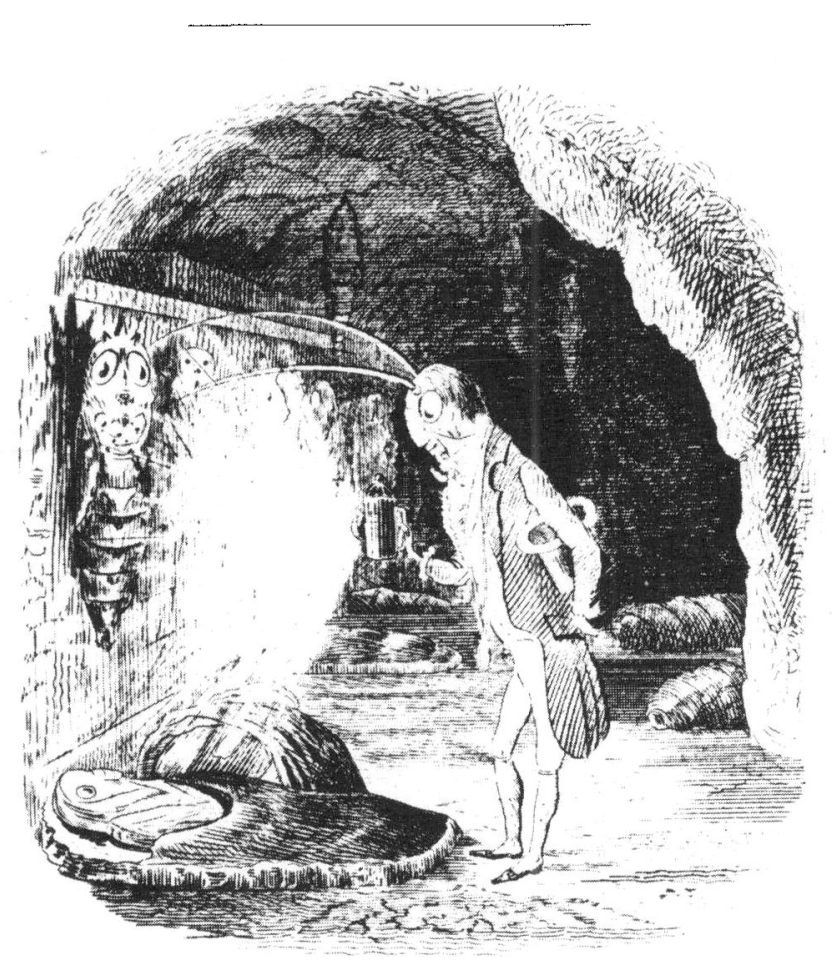

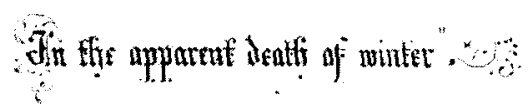

FIG. 1. 'No doubt, Sir, an Entomologist' - humour, coupled with respect for insects, in the Victorian era. From Episodes of Insect Life, written under the pen-name of Acheta domestica. M.E.S. (i.e. Member of the Entomological Society), in 1849 (London: Reeve, Benham \& Reeve, $320 \mathrm{pp}$.). 